\title{
Tsafon
}

Revue d'études juives du Nord

$75 \mid 2018$

Exil des langues - Langues d'exil

\section{Elsa Quinette et Benoit Manent, La visite de monsieur Jacubowiez}

Andrée Lerousseau

\section{(2) OpenEdition}

1 Journals

Édition électronique

URL : https://journals.openedition.org/tsafon/762

DOI : $10.4000 /$ tsafon.762

ISSN : 2609-6420

Éditeur

Association Jean-Marie Delmaire

Édition imprimée

Date de publication : 1 juin 2018

Pagination : 189-190

ISSN : 1149-6630

\section{Référence électronique}

Andrée Lerousseau, «Elsa Quinette et Benoit Manent, La visite de monsieur Jacubowiez », Tsafon [En ligne], 75 | 2018, mis en ligne le 06 mai 2019, consulté le 24 juin 2021. URL : http:// journals.openedition.org/tsafon/762 ; DOI : https://doi.org/10.4000/tsafon.762

Ce document a été généré automatiquement le 24 juin 2021.

Tsafon. Revues d'études juives du Nord 


\title{
Elsa Quinette et Benoit Manent, La visite de monsieur Jacubowiez
}

\author{
Andrée Lerousseau
}

\section{RÉFÉRENCE}

Elsa Quinette et Benoit Manent, La visite de monsieur Jacubowiez. Avec Isidore Jacubowiez et les élèves du collège Bernard Palissy, $40 \mathrm{~min}, 2017,10 €$. Pour toute commande :

AMEJD 10 (Association pour la Mémoire des Enfants juifs déportés du $10^{\text {ème }}$ arrondissement), 100, Rue Pelleport, 75020, Paris.

1 Le visiteur, Monsieur Jacubowiez, est un ancien enfant caché, élève de l'école élémentaire devenue aujourd'hui le collège Bernard Palissy, dans le $10^{\text {ème }}$ arrondissement de Paris, dont la mère disparut à Auschwitz, et qui, depuis 18 ans, vient chaque mois de janvier témoigner devant les collégiens de ce qu'il nomme - ou plutôt ne nomme pas - "cette chose-là », en mémoire des 16 enfants et adolescents fréquentant l'établissement qui furent déportés et assassinés et dont les noms figurent sur la plaque dévoilée en 2000. Mais par-delà le scandale, il entend également évoquer la solidarité des habitants du quartier et exprimer sa gratitude à cette école qui, dit-il, « lui a sauvé la vie », à ses copains d'antan qui ne l'ont jamais dénoncé, tant il était en tout point semblable à eux, alors que, poussé par la concierge qui l'hébergeait, il poursuivit là sa scolarité, sans porter l'étoile jaune, d'octobre 1940 à 1943, avant de passer clandestinement en Suisse.

2 C'est l'une de ces visites qu'ont filmée Elsa Quinette, auteure entre autres d'un remarquable documentaire intitulé La vie est ailleurs (2011), et Benoit Manent, artiste et professeur d'arts plastiques au collège. Véritable leçon de pédagogie, le court métrage est un film sur l'écoute et le dialogue. En marge des discours convenus autour du «plus jamais ça ", mot d'ordre dont on mesure aujourd'hui l'incapacité à pénétrer les consciences, la caméra s'attarde sur l'essentiel, sur cela même qui fonde la relation à autrui. Ce qui frappe, c'est le regard bienveillant que pose Monsieur Jacubowiez sur un 
auditoire qui capte son attention avant même qu'il ne prenne la parole, c'est cette prévenance discrète qui lui fait immédiatement percevoir la diversité de son public et un pan de l'histoire de chacun de ces adolescents. Il débute son récit par l'évocation de Jacqueline dont la famille fut arrêtée en 1942 en tentant de franchir la ligne de démarcation. Si la petite fille, âgée de 10 ans, dut son salut à la mansuétude d'un soldat allemand, son frère, Raymond Rosenblum dont le nom figure sur la plaque, n'eut pas cette chance.

Pour un rappel de ce passé terrible, le visiteur d'un jour sait trouver les mots justes, les définitions simples et claires, mais il trouve aussi la formule pour désamorcer la tristesse et le désarroi perceptibles dans les questions des adolescents qui vont d'emblée à l'essentiel, à la dimension abyssale de cette " chose » : « Pourquoi ils tuaient des enfants? ", «Ont-ils déporté des bébés? ", «Comment vivre à nouveau lorsque sa mère ne revient pas ? "... Si le visiteur n'est certainement pas là pour bercer ces jeunes d'illusions, il ne leur parle pas moins de la vie, de la difficulté et de la nécessité de vivre " après ». Et tout comme le regard de Monsieur Jacubowiez, la caméra s'attarde longuement et fait constamment retour sur le visage de ces jeunes, sur leur silence empli d'écoute et parfois de détresse.

Les visages des collégiens d'aujourd'hui font écho, dans cet espace qui leur est commun, à ceux des enfants et adolescents déportés dont les photos prises à différents moments de leur vie assassinée (des instants parfois de bonheur et d'intimité en famille) se détachent sur les murs, et ils nous requièrent, s'imposent à nous, exposés dans leur vulnérabilité et leur fragilité, expression d'une humanité à sauvegarder. Toutes les formes de totalitarisme (passées, présentes et à venir) ne s'acharnent-elles pas à vouloir gommer ou éradiquer le visage? Si cette "archive » se distingue des autres, c'est par cette écoute réciproque qui est donnée à voir, par cette émotion palpable même lorsque certains s'efforcent de la masquer, tête baissée derrière un poing fermé -, c'est par la place ménagée au silence, le temps d'appréhender cette «chose » que jamais l'on ne parviendra à cerner.

C'est pourquoi il faudra projeter ce film aux générations à venir, en faisant le pari qui peut sembler un peu fou, que les paroles et les images, que ces visages qui leur ressemblent sauront retenir leur attention et forcer leur écoute. Le documentaire se termine par une prise de vue, de dos, du visiteur qui s'éloigne, son grand carton à dessin renfermant les documents soigneusement choisis pour ces jeunes sous le bras. Et l'on est frappé, saisi, par la grande dignité qui émane de toute la personne de Monsieur Jacubowiez. 